\title{
BACTERIOLOGICAL AND EPIDEMIOLOGICAL ASPECTS OF MASTITIS IN ARAK AREA DAIRY HERDS (IRAN)
}

\author{
M.Mahzounieh ${ }^{1}$, Gh.Zadfar ${ }^{2}$,Sh.Ghaem Maqami ${ }^{2}$, N.Shams $^{3}$ \\ ${ }^{1}$ Dep. Of Pathobiology, Faculty of veterinary medicine, Shahrekord university, Shahrekord, Iran \\ ${ }^{1}$ Correspondence address: P.O.Box 115,Shahrekord university, Shahrekord, Iran. Tel.+983814424427, \\ Fax:+983814424412,E-mail: mahzoon@yahoo.com \\ ${ }^{2}$ Veterinary research center, Jahad sazandegi, Arak, Iran \\ ${ }^{3}$ Dep. Of Clinical science, Faculty of veterinary medicine, \\ Shahrekord university, Shahrekord, Iran
}

\section{Objective}

The purposes of this study were to determine of prevalence of mastitis in dairy herds and identify the main pathogens in Arak area dairy herds in 1999-2000

\section{Introduction}

Subclinical mastitis is responsible for major economic losses to dairy industry and more-effective therapeutic or preventive approaches are sorely needed on the bases of determining the prevalence rate and causative agents in any area.

\section{Materials and methods}

A total of 5364 quarters of 1341 animals from half of dairy herds of Arak area was examined. Milk samples tested by CMT as routine method. Positive CMT samples cultured by using Mac.conckey and blood agar media. Bacteria isolated from milk samples identified by direct examination microscopy, biochemical reactions, catalase and coagulase production. Clinical mastitis cases were detected by abnormal changes in milk and udder.

\section{Results}

A total of 18 (1.4\%) and 467 (34.8\%) showed clinical and subclinical mastitis in 1341 cows respectively. Out of 561 milk samples from 485 dairy Cow with positive CMT results which tested, 163 (29\%) yielded no bacterial growth. Of bacteria isolated, 203 (51\%) were coagulase-positive Staphylococcus, 98 (24.62\%) were Streptococcus agalactiae, 36 (9.04\%) were coagulase-negative Staphylococcus, 7 (1.76\%) were S.uberis, $2(0.5 \%)$ were S.disgalactiae, $12(3.01 \%)$ were S.fecalis, 19 $(4.77 \%)$ were Actinomyces pyogenes, 7 (1.76\%) were E.coli, 8 (2.01\%) were B.cereus, 4 (1\%) were micrococcus spp. And 2 (0.5\%) were yeast spp.

\section{Conclusions}

Results showed that mastitis has high prevalence (36.2\%) in dairy herds of Arak area. Most cases were associated with Staphylococcus spp. Bacteria (75.62\%); therefore, we have to evaluate the previous preventive approaches and focused on dry cow therapy to reduce losses of this production disease. 